\title{
CONSELHEIROS DO ORÇAMENTO PARTICIPATIVO NAS FRANJAS DA SOCIEDADE POLÍTICA
}

WAGNER DE MELO ROMÃO

Este artigo sugere a necessidade da mudança de enfoque dos estudos sobre as novas instâncias de participação na gestão de políticas públicas, surgidas na redemocratização brasileira. Afastando-se da literatura que preconiza o papel da sociedade civil nessas instâncias, são revistos os estudos sobre o Orçamento Participativo (OP) que indicam como tais experiências são marcadas pelas dinâmicas da sociedade política. $\mathrm{O}$ argumento é reforçado pela apresentação de pesquisa realizada junto a conselheiros do OP de Osasco-SP, pela qual se percebe uma atuação permeada pelos processos políticos próprios da democracia representativa. A maioria dos conselheiros compõe as franjas da sociedade política, situam-se em ascensão a ela, buscando melhor posicionamento no campo político local, no âmbito das disputas 
internas aos partidos e ao governo municipal. Apontam-se, então, os limites do potencial democratizante do OP, pois a ampliação da participação nas decisões sobre o orçamento se daria apenas para dentro da própria sociedade política.

Palavras-chave: Orçamento Participativo, sociedade política, sociedade civil, participação, governo local.

Recebido: 20/02/2011 Aprovado: 05/09/2011

\section{PARTICIPATORY BUDGETING COUNSELORS IN THE FRINGES OF POLITICAL SOCIETY}

This article suggests the need for change in focus of studies on new instances of participation in public policy management, which emerged in the Brazilian re-democratization. Moving away from the literature that addresses the role of civil society in these instances, the author reviews studies on Participatory Budgeting (PB) indicating how such experiences are marked by the dynamics of political society. The argument is reinforced by the presentation of a survey of $P B$ 360 counselors in Osasco-SP, by which we perceive, in general, a role filled by political processes of representative democracy. Most councilors compose the "fringes" of the political society, lie on the rise in, seeking better position in the local political field, internal disputes within the parties and the municipal government. This points the limits of the democratizing potential of the $P B$, since the expansion of participation in budget decisions would be just within the political society.

Keywords: Participatory Budgeting, political society, civil society, participation, local government. 


\section{CONSELHEIROS DO ORÇAMENTO PARTICIPATIVO NAS FRANJAS DA SOCIEDADE POLÍTICA}

Wagner de Melo Romão

O debate acadêmico sobre as relações entre a sociedade civil e o Estado tem se intensificado nos últimos anos, com destaque para as investigações sobre a participação da sociedade civil nos assuntos governamentais concretizada, sobretudo, nos conselhos gestores de políticas públicas. Gradativamente, os estudos sobre tais instâncias e sobre outras modalidades de relacionamento entre sociedade civil e Estado têm abandonado a visão que identificava aquela exclusivamente ao polo da cultura política democrática desta oposição (Avritzer, 1996). Cada vez mais se destaca a sociedade civil como um campo heterogêneo e permeado por relações mais ou menos intensas com a sociedade política (Feltran, 2006; Coelho e Favareto, 2007; Castello, Gurza Lavalle e Houtzager, 2009; Cornwall, 2009; Maia, 2010), especialmente quando o foco da discussão se dá sobre os conselhos de políticas públicas.

No que se refere às experiências de Orçamento Participativo (OP), tal divisão se coloca de maneira semelhante, embora com outro matiz. Há estudos que avaliam os sucessos e fracassos das experiências de OP, ou pela capacidade 
da sociedade civil manter sua autonomia frente ao atores estatais e partidos políticos, ou pela vontade política dos governantes em criar e manter o OP, de preferência zelando por deixá-lo livre de pressões dos parlamentares locais (Avritzer, 2003, 2009; Teixeira, 2003; T. Silva, 2003; Neves, 2008). Nesses trabalhos, os atores e processos políticos próprios da democracia representativa são vistos como nocivos ao OP e pouco se avança em uma compreensão do fenômeno que incorpore tais atores e processos à análise.

Outro conjunto de trabalhos (M. Silva, 2003; Wampler, 2004, 2007; Nylen, 2002; Filomena, 2006; Teixeira e Tatagiba, 2005; Ottmann, 2006; Rodgers, 2009; Baierle, 2002; Gurza Lavalle, Houtzager, Acharya, 2004) buscou produzir uma leitura mais fina sobre os fundamentos da participação no OP, gerando uma visão alternativa à chave da autonomia/cooptação da sociedade civil e da vontade política dos governantes como elementos definidores do debate sobre o 220 OP. Nesses textos é possível detectar a existência de ligações mais complexas entre a dinâmica da participação no $\mathrm{OP}$ e as instituições da sociedade política. Assim, forneceram interpretações e achados que inspiraram a proposta teórico-metodológica deste artigo.

A pesquisa de campo realizada para a elaboração deste artigo $^{1}$ se compôs de entrevistas realizadas junto aos conselheiros do OP de Osasco, entre os meses de outubro e novembro de 2009, além de entrevistas exploratórias com membros da coordenação do OP e da Câmara de Vereadores do município. A estratégia seguida foi a de caracterizar os vínculos entre os membros do Conselho do Orçamento Participativo (COP) de Osasco e as instituições e processos da sociedade política local. Evidentemente, não se deixou de considerar os possíveis vínculos dos conselheiros com

\footnotetext{
${ }^{1}$ As primeiras análises sobre os dados obtidos nesta pesquisa podem ser verificados na minha tese de doutorado (Romão, 2010a).
} 
instituições da sociedade civil (movimentos sociais, organizações civis, sindicatos, igrejas etc.).

Os resultados obtidos foram contundentes no sentido de apontar uma forte relação dos principais tomadores de decisão no processo participativo - os conselheiros - com a sociedade política, muito mais do que com as entidades da sociedade civil. Há, em realidade, uma divisão clara entre os membros do COP de Osasco, verificada a partir do tratamento dos dados obtidos por meio das entrevistas: a maioria dos conselheiros está disposta a atuar no jogo político local e considera o OP como um espaço privilegiado de visibilidade e acesso à sociedade política. Formam o grupo de jogadores. Por outro lado, há uma minoria de conselheiros que tende a se distanciar das instâncias do OP, seja por considerá-las pouco efetivas na determinação do orçamento público do município, seja pela percepção de que se trata de um espaço permeado pelos vícios da política tradicional. Formam o grupo de idealistas.

Entre os jogadores, há outra distinção: aqueles ligados ao partido político mais relevante no cenário político local - no caso, o PT - tendem a ser elementos pouco graduados na estrutura organizacional do partido. Ao contrário, os conselheiros ligados a partidos menos fortes em Osasco (PMDB, PSB, PV, PTN) ocupam lugar de destaque em suas legendas, com cargos nos diretórios locais e, eventualmente, lançando-se candidatos a vereador. Para os petistas, o OP configura-se como um dos principais canais de contato e de relação entre as bases partidárias e os membros do governo, vereadores e lideranças locais pertencentes ao próprio PT - confirmando teses presentes em Wampler (2004). Os membros/líderes de outros partidos, de outro modo, atuam de maneira a conquistar mais filiados a seu partido ou a estabelecer interlocução com futuros apoiadores e eleitores. Assim, os sentidos da participação - relacionados, no caso dos jogadores, à sua valorização no âmbito da sociedade 
política - obedecem à posição específica de cada conselheiro no contexto político local.

Além desta introdução, este texto compõe-se de mais cinco tópicos. No segundo, será discutida a literatura sobre o OP, tanto aquela marcada pela chave da autonomia/cooptação da sociedade civil como a de visão alternativa a esta. No terceiro tópico, será apresentada a metodologia e instrumental utilizado na pesquisa junto ao OP de Osasco-SP. No quarto, são expostos os principais resultados da pesquisa. $\mathrm{O}$ quinto tópico expõe a análise desses resultados e da elaboração dos dois tipos de conselheiros do OP, os jogadores e os idealistas. Por último, como de praxe, são apresentadas as considerações finais do artigo.

\section{Sociedade civil e sociedade política nos estudos sobre 0 orçamento participativo}

Talvez o principal intérprete e divulgador das experiências

222 de OP seja Leonardo Avritzer (2002a, 2002b, 2003, 2005, 2009; Avritzer e Wampler, 2004) ${ }^{2}$. O autor tem uma vasta produção teórica sobre o tema da democracia participativa e deliberativa, na qual o OP tem ocupado lugar de destaque. Em seus textos, Avritzer destaca a centralidade da sociedade civil no funcionamento dessas instâncias. Seu modelo de OP, pelo qual invariavelmente estrutura seu argumento, é a experiência de Porto Alegre. Embora o autor considere que o OP teria nascido através da "ação pública de atores variados", defende que a "tradição associativa" (Avritzer, 2002a, p. 145) gaúcha teria sido responsável pelas raízes mais primordiais do OP. A particularidade do processo de formação social e econômica do Rio Grande do Sul e a tradição política do estado teriam gestado "elementos mais fortes de uma sociabilidade igualitária que contribuíram na formação de

\footnotetext{
2 Para uma análise detalhada dos estudos de Leonardo Avritzer sobre o OP, ver Romão (2010a).
} 
elementos associativos mais fortes do que no resto do país no século XX" (Avritzer, 2003, p. 21). Processos de organização social ocorridos na década de 1950 e 1960 e, depois, nos anos da redemocratização, teriam gerado um associativismo mais denso e reivindicativo (Avritzer, 2003, p. 22). Reflexo disso seria o uso do termo "orçamento participativo" em documento da União das Associações de Moradores de Porto Alegre (Uampa) ${ }^{3}$. Seria esta uma evidência empírica do protagonismo da sociedade civil no OP, continuamente mencionada em seus textos.

É certo, entretanto, que havia um elevado grau de partidarização das direções da Uampa desde os primeiros momentos de sua fundação, em 1983. Baierle (1992) indica que estas se revezavam entre a influência do PT e do PDT, nas disputas pela diretoria da entidade. Os presidentes da Uampa foram Waldir Bohn Gass (1984-1988) - petista que depois, em 1989, seria eleito o primeiro presidente municipal do PT da capital gaúcha - e Paulo Guarnieri (1989-1992), este filiado ao PDT. Ainda segundo Baierle (1992, p. 67), "todos os anos de realização de congressos pela Uampa foram anos eleitorais, o que parece indicar a utilização destes eventos como instrumento de campanha eleitoral pelas oposições”.

Ao invés de se constituírem como um elemento da análise, a omissão a tais informações no que seria o ponto de

\footnotetext{
3 “O primeiro documento por nós localizado, no qual aparece a expressão 'Orçamento Participativo', é um documento da Uampa [...]. Em uma reunião realizada em 26 de março de 1986, com o objetivo de discutir a participação dos movimentos populares no governo Alceu Collares (PDT), aparece o diagnóstico acerca da centralidade do orçamento público: 'o mais importante na Prefeitura é a arrecadação $e$ a definição de para onde vai o dinheiro público. É a partir dai que vamos ter ou não verbas para o atendimento das reivindicações das vilas e bairros populares. Por isso, queremos intervir diretamente na definição do orçamento municipal e queremos controlar sua aplicação'. $\mathrm{E}$, mais à frente, o documento diz: 'queremos decidir sobre as prioridades de investimento em cada vila, bairro e da cidade em geral. Este parece ter sido o ponto de partida para um processo no qual o orçamento e sua elaboração foram se tornando os elementos centrais do debate político na cidade de Porto Alegre" (Avritzer, 2002b, p. 28).
} 
partida do OP marca a abordagem de Avritzer. Coerente com essa visão, a presença da sociedade política e suas dinâmicas no OP, ou é ocultada, ou é vista como sinal de incompletude e deficiência do processo participativo, pois indica a virtual inexistência de autonomia da sociedade civil, elemento identificado também com falta de "tradição associativa" em determinada localidade.

Mesmo em trabalho recente sobre o tema (Avritzer, 2009), em que pretende incorporar a sociedade política às suas análises, o autor limita-se a considerar partidos políticos e governos apenas com relação à vontade política em se implantar ou não propostas participativas. Isto é, a relação do OP com partidos e governos permanece sendo vista como algo externo ao processo de participação e suas instâncias, postura semelhante à adotada em seus trabalhos anteriores (Romão, 2010b).

Estudos como o de Tarcísio da Silva (2003) e Teixeira 224 (2003) vertem essa leitura do OP à explicação do fracasso de algumas experiências. Silva se dedica ao estudo do OP de Recife-PE, na administração Jarbas Vasconcellos (PMDB), no período 1993-1996. Além das limitações do desenho institucional e do pequeno percentual orçamentário $(2,5 \%)$ destinado às obras selecionadas pelo $\mathrm{OP}$, o autor entende que também a baixa qualidade da representação da sociedade civil no processo o teria debilitado. Tarcísio da Silva defende que o "modo de fazer política" dos movimentos comunitários de bairro do Recife teria forte ligação "com um modelo centralizador e populista caracterizado, sobretudo, por reivindicações em gabinetes e articulações com vereadores e demais políticos influentes" (2003, p. 305), e pede ainda uma participação mais plural da sociedade civil:

Consideramos fundamental uma análise dos segmentos da sociedade civil envolvidos e de sua relação com o Estado. Consideramos fundamental que se tenha a presença de 
diversos setores da sociedade civil e não apenas a representação da sociedade através dos movimentos comunitários de bairro como se estabeleceu em muitos modelos no Brasil, inclusive no Recife (Silva, 2003, p. 305).

Em outro trabalho, sobre a experiência de pequenos municípios rurais com o OP - entre eles o de Icapuí-CE -, Teixeira constata que naquela cidade "a tradição associativa não é muito forte e os sucessivos governos, desde que o município foi implementado, praticamente criaram a sociedade local" (Teixeira, 2003, p. 208). Verificando que, naquele caso, "63,9\% dos conselheiros do Fórum do OP de Icapuí são funcionários públicos e 8,3\% são prestadores de serviços à Prefeitura", a autora identifica a falta de autonomia da sociedade local como a principal deficiência daquele OP: "Esta discussão sobre o papel do associativismo local e de como ele consegue se inserir no processo do OP nos remete à discussão sobre a fragilidade da sociedade civil e de como é necessária a autonomia da sociedade civil" (Teixeira, 2003, p. 209).

Às teses da "sociedade civil imperfeita" juntam-se às da "vontade política débil", relacionada à cultura política autoritária própria do Estado brasileiro (Avritzer, 1996). Em análise sobre a experiência de Barra Mansa-RJ entre 1997 e 2000 (Neves, 2008), o OP é inicialmente visto como expressão da cultura política democrática, mas que teria perdido força por pressão dos vereadores. Na articulação do OP com a sociedade política local, "os representantes da sociedade civil [...] se contaminaram pela lógica do favor existente como prática habitual" (Neves, 2008, p. 178). Instituiu-se o chamado Mutirão Democrático, pelo qual uma vez que não fosse possível a execução do que fora aprovado no OP, havia um "apadrinhamento" das obras pelo vereador de base política no bairro, em concordância com a associação de moradores local e a prefeitura. Para a autora, a vincula- 
ção entre o Orçamento Participativo e o Mutirão Democrático clientelista caracterizaria uma "cultura política ambígua" ou "sincrética" (Neves, 2008, p. 188) ${ }^{4}$. No ato de garantir governabilidade frente ao Legislativo hostil, tratou-se de manter o OP como a referência básica para o Mutirão, conciliando-se novas e velhas práticas políticas. Permanece a explicação do fracasso ou equívoco dos OPs pelas carências da sociedade civil ou pela ausência de vontade política dos governos municipais, tíbios no confronto com os ranços da política tradicional.

Abordagens distintas a esta e, sobretudo, metodologias de pesquisa menos restritas à temática da sociedade civil, geraram os trabalhos que serão indicados a seguir. Eles fornecem elementos para que se busque estruturar uma proposta analítica do OP cujo centro esteja na sociedade política, e não na sociedade civil.

Mércia Silva (2003) destaca como são travadas as dis226 putas sobre o local de realização das assembleias do OP, elemento que, na prática, estabelece as condições iniciais para a maior ou menor presença de cada uma das comunidades no processo. A questão do transporte é estratégica e a proximidade com vereadores e deputados é a garantia de que se conseguirão recursos para o aluguel de ônibus para que a comunidade vá às assembleias. A autora também indica como as decisões da regional Venda Nova são centralizadas pelo chamado grupo dos "cobras", constituído por seis lideranças. Esse grupo fechado, permeado por ligações com membros do Poder Legislativo e/ou com partidos, demonstra maior capacidade de enfrentamento às propostas de obras do governo e decide quais devem ser realizadas, pois cada um de seus integrantes tem controle sobre determinada quantidade de participantes do OP e, em decorrência disso, elegem seus delegados.

4 Tal vinculação também é feita em Ricci (2004). 
Wampler (2004), em survey aleatório via telefone, realizado em 2003 com uma amostra de delegados do OP de São Paulo, indica que $37 \%$ disseram pertencer a algum partido político, sendo que dentre eles, $87 \%$ disseram pertencer a partidos considerados de esquerda - PT, PSB, PCdoB e PV. Carvalho e Felgueiras (2000) indicaram como, entre os conselheiros do OP de Santo André, no período de 1997-1998, 47\% eram filiados ao PT, proporção referente apenas aos representantes da sociedade civil, uma vez que naquela cidade o COP era paritário entre membros do governo e os delegados eleitos nas plenárias. Essa proporção é semelhante à encontrada por Neves (2008), no COP de Barra Mansa-RJ. Nylen (2002) desenvolveu pesquisa em Belo Horizonte e em Betim-MG. O autor constatou que o OP atraía mais aqueles agentes sociais já engajados em atividades políticas. Em 1998, realizou survey com os delegados do OP, constatando que, em Belo Horizonte, 23,5\% eram filiados a partidos políticos. Em Betim, o índice foi de 39,3\%.

Filomena (2006) apurou que no COP de Porto Alegre, entre 1992 e 2004, os conselheiros próximos ao PT sempre representaram frações próximas ou superiores a $40 \%$ de seus membros. Baierle (2002) indicou que, segundo pesquisa da ONG Cidade junto aos dirigentes de associações de moradores que participaram das plenárias do OP porto-alegrense, $13,8 \%$ eram ligados a partidos políticos. Sobre esse mesmo público, mas apenas dentre aqueles que se elegeram delegados, o número subia para 21,6\%, e daqueles dentre estes que chegaram a ser eleitos conselheiros do OP, 31,8\% eram filiados a algum partido político. Pode-se considerar que esse número poderia ser maior em se tratando das ligações da totalidade dos conselheiros a algum partido político, e não apenas daqueles dirigentes de associações de moradores.

Rizek (2007), em trabalho sobre o OP paulistano, verificou o livre-trânsito de delegados e conselheiros do OP em assessorias de vereadores e deputados. Teixeira e Tatagiba 
(2005), também em estudo sobre o OP de São Paulo, apontaram como delegados e conselheiros invariavelmente eram eleitos por indicação de vereadores. Essa situação foi também analisada por Ottmann (2006). Gurza Lavalle, Houtzager e Acharya (2004) verificam uma estreita correlação entre a participação nos conselhos municipais de políticas públicas e no OP da cidade de São Paulo e os vínculos entre os atores da sociedade civil e o PT, então no comando da prefeitura paulistana, apontando a necessidade de se verificar com mais acuidade as influências entre os atores da sociedade civil e o sistema partidário.

No caso de Buenos Aires, como assinala Rodgers (2009), a criação do $\mathrm{OP}$ portenho teria respondido à necessidade do prefeito Aníbal Ibarra de ampliar apoios internos e externos ao seu partido no governo, no contexto da crise política na Argentina nos primeiros anos da década de 2000. A gestão do OP foi delegada a um grupo interno à Frente Grande, o 228 Grupo Espacio Abierto, preocupado em ampliar suas redes políticas na cidade. O coordenador do OP de Buenos Aires, Ariel Schifrin, líder do Espacio Abierto,

inseriu rapidamente pessoas de confiança em todas as dezesseis administrações descentralizadas e centros de participação (os Centros de Gestión y Participación, CGPs), com a instrução de que deveriam garantir uma forte presença partidária nos processos do OP que estavam sendo instituídos pelos CGPs (Rodgers, 2009, p. 211-212).

Todos esses estudos indicam uma considerável relação entre as disputas próprias às instituições políticas tradicionais (ou da democracia representativa) e as esferas decisórias das experiências de OP. A filiação a um partido político, geralmente o partido governista, é algo bastante comum nas instâncias superiores do OP (conselhos e fóruns de delegados), e se torna mais frequente quanto mais se sobe 
na escala de importância para a decisão final sobre a proposta orçamentária.

A literatura aponta a necessidade de se avançar, tanto teórica quanto metodologicamente, na compreensão dos sentidos desta proximidade entre as instituições políticas tradicionais e as experiências de OP. A proposta metodológica produzida com esse intento será apresentada a seguir.

\section{A metodologia e 0 instrumental de pesquisa utilizado}

A metodologia de pesquisa aqui proposta tem dois elementos fundamentais: em primeiro lugar, busca distanciar-se das técnicas que caracterizam as experiências de OP a partir de surveys realizados para se obter o perfil socioeconômico dos participantes deste, geralmente realizados ou encomendados pelos governos municipais (Fedozzi, 2001; Sanchez, 2002). Nesses estudos fica obnubilada a dimensão propriamente política desses espaços de participação, pois o instrumental metodológico não permite aos pesquisadores captar as propriedades de sua dimensão representativa, em que delegados são eleitos como representantes das regiões da cidade na instância máxima decisória, o COP. Em geral, nesses surveys não se observa relação entre os participantes e as instituições políticas tradicionais (partidos, governos, processos eleitorais), seja por que essa dimensão não é explorada no instrumento de pesquisa, seja por que, ao se considerar as centenas ou milhares de participantes nas plenárias de OP, o vínculo entre tais instituições e as principais lideranças comunitárias fica subdimensionado. Considerando que a principal inovação democrática do OP é a tomada de decisão sobre o orçamento compartilhada com a população - para além de seus eventuais efeitos pedagógicos (Pontual, 2000; Pereira, 2007) e redistributivos (Marquetti, Campos e Pires, 2008) - a proposta aqui é investigar a dinâmica política do COP, estrutura que se encontra no ápice do processo de participação e em que a dimensão representativa do OP se coloca com mais força. 
Em segundo lugar, trata-se de não preestabelecer vínculos entre as entidades da sociedade civil e o OP na metodologia de pesquisa. Embora com enfoques e conclusões diversas, parte significativa das pesquisas realizadas se dedica a identificar relações entre as entidades da sociedade civil e as novas instâncias de participação (Avritzer, 2002b; Gurza Lavalle, Houtzager e Acharya, 2004). O presente artigo não foi escrito com esse intuito. Ao contrário, o teste que se buscou efetuar foi o de verificar em que medida preponderavam os vínculos dos conselheiros com a sociedade civil e/ou a sociedade política.

A metodologia utilizada, portanto, combinou o foco sobre o COP e a elaboração de um instrumento de pesquisa que não se prendeu à dimensão da sociedade civil, mas incorporou questões para que se pudesse aferir também os vínculos do entrevistado com a sociedade política.

O principal instrumento de pesquisa utilizado foi um 230 questionário, aplicado aos representantes eleitos ao COP de Osasco. Ele foi dividido em três partes: a primeira produzia um perfil socioeconômico do entrevistado, com questões sobre sua renda familiar, grau de escolaridade, tempo de moradia em Osasco e outros aspectos.

A segunda parte buscava caracterizar as relações sociopolíticas do entrevistado, segundo as seguintes diretrizes:

1. manter foco duplo na caracterização dos vínculos do representante, tanto sobre as instituições da sociedade civil como sobre instituições e práticas ligadas à sociedade política, buscando-se, assim, evitar que o instrumento de pesquisa atuasse para reforçar um ou outro componente da vida - associativa ou política - do conselheiro;

2. qualificar o vínculo do conselheiro a determinadas instituições e práticas sociopolíticas. Buscou-se detalhar aspectos como: liderança na instituição; efetividade da filiação/associação; nível de representação/vínculo; tempo de permanência na instituição etc.; 
3. especificamente quanto aos vínculos com a sociedade política, estabeleceu-se a análise em quatro pontos principais: a) filiação a partidos políticos; b) nível de envolvimento com o processo eleitoral imediatamente anterior; c) participação em plenárias e reuniões políticas de vereadores e deputados; d) desejo de candidatar-se a vereador ou outro cargo público. Para fins analíticos, estes quatro pontos (a, b, c, d) se converteram em um indice de envolvimento político, que se conformou no elemento essencial da pesquisa ${ }^{5}$.

A terceira e última parte do questionário se referiu à caracterização da relação do entrevistado com o $O P$, que deveria ser percebida a partir das seguintes preocupações investigativas: a) tempo de contato com o OP e número de mandatos como conselheiro; b) autodeclaração sobre as motivações para a participação no OP e detalhamento do processo de eleição do conselheiro para seu cargo; c) relação com a coordenação do OP e com os outros conselheiros; e d) declaração sobre os principais sucessos e fracassos do OP. Os dados obtidos aqui foram decisivos para se estabelecer as caracterizações dos tipos de conselheiros, que serão apresentados no tópico cinco.

Foi estabelecida a meta de entrevistar o máximo possível de conselheiros do mandato 2007-2009. Em uma entrevista exploratória com a coordenação do OP -, em que foi esboçada

\footnotetext{
${ }^{5}$ Para a construção do índice, foi estabelecida a seguinte metodologia de análise das respostas dos conselheiros: a elas, foram imputados valores de 0 a 1 , conforme a resposta fosse negativa (zero/0) ou positiva (um/1); por adição, gerou-se uma escala de valores, de 0 a 4 , que compuseram níveis de envolvimento político. A questão b, relativa à participação em campanha política, apontava seis possibilidades de resposta, organizadas de maneira crescente com relação à intensidade na participação nas eleições, desde "apenas votei" até "fui candidato". Nessa questão, optou-se por dar valor 0 (zero) ao primeiro estrato e 1 (um) aos outros cinco níveis. De modo semelhante, a questão c, relativa à participação em plenárias de políticos, apontava cinco estratos, desde o primeiro "nunca fui" até o quinto e último "fui mais de dez vezes". Nessa questão optou-se por dar valor 0 (zero) ao primeiro nível e 1 (um) aos outros quatro estratos. Para mais detalhes, remeto o leitor à minha tese de doutorado (Romão, 2010a).
} 
uma primeira visão de seu funcionamento - foram obtidos os contatos dos integrantes do COP. A lista continha 56 nomes, entre conselheiros titulares e suplentes. Foi possível efetuar 32 entrevistas por telefone, sendo 23 com representantes titulares e 9 com suplentes. Cabe salientar que, pelo Regimento do OP, os conselheiros que compõem o COP são 46, sendo 5 representantes do OP Jovem, 5 representantes indicados por entidades comunitárias e associações da sociedade civil e 36 representantes das 18 regiões do OP na cidade.

\section{Principais resultados da pesquisa}

A tabela abaixo é composta pelos resultados da aplicação do índice de envolvimento político aos conselheiros entrevistados.

Tabela 1

Conselheiros entrevistados e nível de envolvimento político

\begin{tabular}{|c|c|c|}
\hline Pontuação / Nível de envolvimento político & n. de conselheiros & $\%$ \\
\hline 0 / nenhum & 2 & 6,2 \\
\hline 1 / baixo & 3 & 9,4 \\
\hline 2 / moderado & 6 & 18,7 \\
\hline 3 / alto & 13 & 40,6 \\
\hline 4 / muito alto & 8 & 25,1 \\
\hline TOTAL & 32 & 100 \\
\hline
\end{tabular}

Verifica-se que, somados, aqueles que possuem "alto" ou "muito alto" envolvimento político representam 65,7\% dos conselheiros. Estes estão plenamente engajados em processos típicos da prática da política institucional, como a participação ativa em campanhas eleitorais, o acompanhamento de mandatos parlamentares, a filiação a partidos políticos e a uma eventual disputa pela vereança. A maioria dos conselheiros, portanto, possui grande afinidade com processos e situações que caracterizam o campo de disputas da sociedade política.

Destaca-se a alta incidência de conselheiros filiados a partidos políticos (são 23 ou 71,9\%). Se considerarmos que, 
além dos conselheiros filiados, existem 5 conselheiros que se declararam "simpatizantes" (sendo 4 do PT e 1 do PSC), esse número dos direta ou indiretamente envolvidos com partidos políticos sobe para 28 , ou $87,5 \%$ do total de entrevistados.

Destes, relacionam-se diretamente com o PT 13 filiados e 4 simpatizantes, ao todo 17 conselheiros (53,1\% dos entrevistados). Demonstra-se, assim, um universo de participação que, embora seja fortemente dominado por petistas, apresenta considerável pluralidade: outros 3 conselheiros são filiados ao PSB e 2 ao PV. Cada partido, entre DEM, PDT, PMDB, PTB e PTN, possui um filiado no COP.

Tabela 2

Ligação dos conselheiros com partidos políticos

\begin{tabular}{|c|c|c|c|c|c|c|c|c|c|c|}
\hline & PT & PSB & PV & DEM & PDT & PMDB & PTB & PTN & PSC & TOTAL \\
\hline Filiados & 13 & 3 & 2 & 1 & 1 & 1 & 1 & 1 & - & 23 \\
\hline Simpatizantes & 4 & - & - & - & - & - & - & - & 1 & 5 \\
\hline TOTAL & 17 & 3 & 2 & 1 & 1 & 1 & 1 & 1 & 1 & $\mathbf{2 8}$ \\
\hline
\end{tabular}

Dos 23 filiados a partidos, apenas um foi dirigente municipal de seu partido (caso de um ex-secretário-geral do PMDB na cidade) e seis conselheiros foram membros dos diretórios municipais (os dois do PV, o do PMDB, o do PTN, um do PSB e um do PT). Isso pode indicar que os participantes do OP vinculados a partidos que não o PT têm mais expressão política interna em seus partidos. Para os petistas, o OP pode configurar-se em um dos principais espaços disponíveis para o início de uma carreira política, ou ao menos para se posicionarem melhor em suas relações com o partido e a sociedade política de maneira geral. Nos partidos de menor expressão na cidade ${ }^{6}$, o OP parece ser um espaço ainda mais estratégico para seu crescimento e ampliação da visibilidade de suas principais lideranças.

6 As disputas eleitorais pela prefeitura de Osasco têm se polarizado entre PT e PSDB, pelo menos desde 2002. Ver capítulo 4 de Romão (2010a). 
Vale salientar que, com relação à ligação dos entrevistados com entidades (ONGs) e movimentos sociais - caracterizados, portanto, no campo da sociedade civil - 12 conselheiros declararam pertencer a ONGs e apenas 4 a movimentos sociais, números bastante inferiores, portanto, ao daqueles que dizem pertencer a partidos políticos.

Com relação ao segundo elemento constitutivo do índice de envolvimento político - a participação na campanha eleitoral de 2008 - também é possível verificar uma alta incidência de conselheiros que se envolveram fortemente naquele pleito. Em primeiro lugar, há 3 conselheiros que se tornaram candidatos a vereador, sendo 2 deles do PV e 1 do PTB, o que fortalece a ideia de que o COP tem dado guarida àqueles que buscam obter visibilidade para candidatar-se à vereança local. Além destes, segundo a coordenadora do OP, existem pelo menos mais 2 conselheiros não entrevistados que também foram candidatos, sendo um do PTN e 234 outro do PT (Romão, 2010a).

Há 4 conselheiros entre aqueles que coordenaram setores das campanhas. Estes exercem uma colocação de confiança perante os candidatos a vereador ou à campanha majoritária situacionista.

Tabela 3

Frequência sobre nível de participação na campanha eleitoral de 2008

\begin{tabular}{|l|c|c|}
\hline PARTICIPAÇÃO NA CAMPANHA ELEITORAL 2008 & n. de conselheiros & $\%$ \\
\hline Apenas votou & 5 & 15,6 \\
\hline Pediu votos no dia da eleição & 1 & 3,1 \\
\hline Participou ativamente de toda a campanha & 13 & 40,6 \\
\hline Foi "profissionalizado" na campanha & 6 & 18,7 \\
\hline Foi coordenador de campanha & 4 & 12,5 \\
\hline Foi candidato & 3 & 9,4 \\
\hline TOTAL & 32 & 100 \\
\hline
\end{tabular}


Os "profissionalizados" ou remunerados são as pessoas que participam da campanha recebendo um salário ou gratificação mensal, os quais contam mais 6 conselheiros. A soma destes três perfis (candidatos, coordenadores e profissionalizados) resulta em 13 conselheiros. Ou seja, 40,6\% dos entrevistados tiveram vínculos extremamente fortes com a campanha eleitoral em 2008. Se considerarmos ainda os outros 13 conselheiros que disseram ter participado ativamente da campanha de maneira voluntária, totalizam-se $81,2 \%$ de conselheiros tendo manifestado sua participação direta na campanha eleitoral.

Quanto ao número de conselheiros que já participou de plenárias de políticos, basta que fiquemos com a quantidade daqueles que declararam ter participado de mais de 10 plenárias, ou seja, aqueles dos quais é possível dizer que têm relativa intimidade com esses espaços, em geral reservados a apoiadores mais ou menos ativos de parlamentares. Estes somam 21 conselheiros, ou $65,6 \%$.

Tabela 4

Participação em plenárias de políticos

\begin{tabular}{|l|c|c|}
\hline PARTICIPAÇÃO EM PLENÁRIAS DE POLÍTICOS & n. de conselheiros & $\%$ \\
\hline Nunca participei & 7 & 21,9 \\
\hline Uma vez & 1 & 3,1 \\
\hline Até cinco vezes & 2 & 6,2 \\
\hline Até dez vezes & 1 & 3,1 \\
\hline Mais de dez vezes & 21 & 65,6 \\
\hline TOTAL & 32 & 100 \\
\hline
\end{tabular}

Essas altas frequências devem ser comparadas com aqueles que declararam querer ser ou que já foram candidatos a vereador. Esse número é menor do que os relativos àqueles que participaram da campanha de 2008 de algum modo ou mesmo dos que são filiados a partidos políticos: 11 conselheiros, ou 34,4\% da amostra responderam 
positivamente à pergunta. Embora este número não deva ser desprezado, afinal, indica que mais que um terço da amostra pretende iniciar uma carreira política, ele também demonstra que o desejo de ser candidato não deve ser o único fator a ser considerado ao deslocarmos o eixo de análise da sociedade civil para a sociedade política.

\section{Conselheiros do OP nas franjas da sociedade política}

Neste tópico relacionaremos os dados apresentados acima com elementos da caracterização de cada um dos entrevistados, realizada a partir da análise das entrevistas.

A Tabela 1 indica os níveis de relação dos entrevistados com fatores relacionados às dinâmicas da sociedade política. Quando são comparados esses níveis com a relação que os entrevistados possuem com o OP, ocorre uma divisão bastante clara entre os conselheiros.

Os conselheiros parecem se dividir em dois grupos: o 236 primeiro grupo constitui um conjunto de agentes sociopolíticos ativos no jogo político local, cuja presença no COP demonstra à sua base social regional e também à classe política da cidade, a posse de capital político suficiente para que se constituam em lideranças. Atuam no âmbito da sociedade política e segundo sua lógica, sem, no entanto, apresentarem condições de se constituírem em protagonistas do jogo, ou seja, situam-se nas franjas da sociedade política (Romão, 2010a). Os componentes desse primeiro grupo são jogadores. Eles constituem a maioria dos entrevistados, situando-se diretamente entre os conselheiros de nível de envolvimento político alto e muito alto, e entre uma parcela dos de nível moderado.

O segundo grupo é composto por conselheiros cujas expectativas com relação ao OP eram de que este fosse um espaço livre das disputas político-partidárias, quase um espaço desprovido dos jogos de poder que caracterizam a política, dedicado exclusivamente à participação da sociedade 
civil nos assuntos do governo. Entretanto, esses conselheiros, críticos às práticas dos jogadores, se decepcionaram com o OP e tendem a se retirar do processo participativo, por vê-lo reproduzir situações que desprezam na política convencional. Sentem-se manipulados pelo processo e passam a compreender que "a política não é coisa para mim". Sua visão é a de que a política é um terreno corrompido, pleno de interesses, e o OP não teria correspondido às expectativas de ser algo diferente. Os integrantes desse são idealistas. Eles constituem uma parcela bastante minoritária dos conselheiros, aqueles que se situam entre os conselheiros de nenhum ou baixo envolvimento político, e pequena parcela dos de índice moderado.

Um elemento importante na caracterização dos idealistas é o fato de que, para alguns destes, o OP não teria se configurado como um espaço de atuação a ser objeto de investimento de tempo: declaram ter deixado de participar do OP para se dedicar a suas atividades profissionais e/ ou pessoais. São indivíduos que não centram na atividade política sua estratégia de engrandecimento pessoal. Não se candidataram à reeleição para um novo mandato como delegados ou conselheiros do OP. É possível considerar que alguns deles sequer tinham intenção em ser conselheiros e acabaram o sendo por força das circunstâncias ou de um convite feito pelos coordenadores do OP. ${ }^{7}$

De maneira distinta, para os jogadores, o OP parece se constituir como o único espaço de atuação política em uma arena pública. É muito relevante o fato de tão poucos conselheiros entrevistados serem sindicalizados - apenas $15,6 \%$ - e de nenhum deles ocupar posição dirigente. No mesmo sentido, como vimos, é ainda menor a incidência de conselheiros que declararam participar de movimentos sociais

7 Foi possível constatar em algumas das entrevistas que alguns daqueles que se tornaram conselheiros receberam convites informais para sê-lo. 
(12,5\%). Uma interpretação plausível desse dado é de que os membros de direções sindicais e de movimentos sociais já possuem seus próprios canais de relacionamento com a sociedade política. Ou seja, atores centrais da sociedade civil, sindicatos e movimentos sociais não só não parecem estar mobilizados para ocupar o espaço do OP como teriam que disputá-lo com indivíduos relativamente avulsos, que buscam ascensão no âmbito da sociedade política. Isto é, embora seja plausível considerar que por meio do OP o governo municipal se torna mais receptivo às demandas externas, parece ser fato que os agentes que efetivamente protagonizam a relação com o governo constituem-se em um grupo bastante vinculado à sociedade política. Em geral, são filiados a partidos e bastante ativos em campanhas eleitorais.

Foi possível constatar que alguns conselheiros possuem ligações explícitas com vereadores eleitos ou secretários. Por outro lado, outros conselheiros indicaram que a vincu238 lação a algum vereador parece ser o caminho para "avançar" no OP: "ali sempre tem que ter um vereador para trabalhar [...] eu não aderi, então a gente tem dificuldade de avançar [...]”. Destaca-se o entendimento do OP como um espaço de visibilidade política: "a gente é muito bem-visto nas secretarias, o prefeito prestigia”. Outro conselheiro declarou que participou do OP "mais pelo meu amigo do PMDB, pra ver se ajudava na (sua) campanha (a vereador)"; outro conselheiro disse: "eu era candidato (a vereador), então queria ter obras no bairro" .

Os dados sobre a reeleição dos conselheiros para o mandato 2009-2011 fortalecem o significado estratégico do pertencimento ao COP. Dos 32 conselheiros entrevistados, 15 se reelegeram, sendo que a proporção mais expressiva está entre aqueles situados no nível alto de envolvimento políti-

\footnotetext{
8 Trechos de entrevistas com conselheiros do OP de Osasco, colhidas em pesquisa telefônica e apresentadas em Romão (2010a)
} 
co. Em 2009, os conselheiros alteraram o regimento interno do OP: previa-se apenas uma reeleição para o COP e, com a mudança, passou a ser permitida a reeleição sem limite de mandatos. Vale acrescentar que pelo menos quatro dos conselheiros não disputaram reeleição porque tinham assumido cargos comissionados na prefeitura ou na Câmara Municipal.

Tabela 5

Envolvimento político x Reeleição para o COP

\begin{tabular}{|c|c|c|c|c|c|}
\hline \multirow{2}{*}{$\begin{array}{c}\text { Reeleição } \\
\text { 2009-2011 }\end{array}$} & \multicolumn{3}{|c|}{ Categorias de envolvimento político } & \multirow{2}{*}{ Total } \\
\cline { 2 - 5 } & $\begin{array}{c}\text { Nenhum/ } \\
\text { Baixo }\end{array}$ & Moderado & Alto & Muito alto & \\
\hline Não & 5 & 3 & 4 & 5 & 17 \\
\hline Sim & 0 & 3 & 9 & 3 & 15 \\
\hline Total & 5 & 6 & 13 & 8 & 32 \\
\hline
\end{tabular}

Segundo a coordenadora do OP, a questão sobre os conselheiros que seriam candidatos a vereador foi debatida fortemente no COP, nos últimos meses de 2009. Ao final, decidiram que os conselheiros que fossem se candidatar deveriam renunciar no prazo legal de desincompatibilização do poder público. O argumento é o de que os candidatos poderiam "se aproveitar do posto, pois eles teriam informação privilegiada”. Segundo a coordenadora do OP, esse tema foi levantado pelos próprios conselheiros, o que reforça o argumento de uma ampla relação desse espaço com as dinâmicas e disputas próprias da sociedade política.

Os limites de um estudo de caso - modalidade de pesquisa da qual se originou este artigo - não devem ser motivo de dúvida quanto à validade dos resultados aqui apresentados, tampouco sobre a relevância analítica da pesquisa, uma vez que aqui se buscou tão-somente aprofundar a discussão 
sobre os vínculos entre a sociedade política e o OP, questão já apontada por boa parte da literatura acadêmica.

A análise do COP de Osasco reforça a necessidade de se refletir sobre o potencial democratizante das experiências de OP, um dos elementos essenciais do debate que vem sendo realizado nos últimos anos sobre as novas instâncias de participação. Ao ser analisada sua instância máxima de decisão comprovou-se que a virtual transferência de poder do Executivo à deliberação pública sobre o orçamento restringe-se a indivíduos fortemente vinculados às disputas políticas locais.

A descoberta que parece ser mais desconcertante, sobretudo para a literatura que ressalta o protagonismo da sociedade civil nessas experiências, é a de que aqueles agentes identificados como idealistas - que se aproximaram do OP por considerá-lo um espaço de participação relativamente protegido das disputas político-partidárias - tendem 240 a se afastar do COP e do próprio OP, por perceberem que o debate público do orçamento parece ficar em segundo plano entre as preocupações da maioria dos conselheiros. Com baixo envolvimento com as instituições da democracia representativa, também se excluem do OP.

À ampla maioria dos conselheiros, que identificamos como jogadores, interessa permanecer no OP. Sentem-se valorizados por pertencer ao COP e veem no processo participativo a possibilidade de aumentar seu capital político e alçar-se a posições mais centrais na sociedade política local. Alguns deles conseguem se agregar a gabinetes de vereadores ou à máquina pública municipal. Parecem satisfeitos com um processo participativo que encurta a distância entre eles e os membros das altas esferas de poder.

Talvez seja apenas este o potencial democratizante de instâncias de participação como o OP: gerar no próprio âmbito da sociedade política uma arena para onde confluem agentes de poder reduzido frente aos protagonistas 
da política local. O OP, desse modo, se configuraria sim, como uma ampliação do processo decisório sobre o destino do orçamento público, mas apenas para dentro da própria sociedade política.

Provavelmente tal abertura restrita à participação deverá ter consequências benéficas para a estabilidade/governabilidade do sistema político local, bem como para a melhoria das relações entre os partidos políticos situacionistas e suas bases sociopolíticas. Se comprovadas, essas suposições podem explicar o motivo pelo qual as novas instâncias de participação permanecem grassando pelo mundo. Mas, colocarão em xeque muitas teorias em voga sobre a democracia participativa.

\section{Wagner de Melo Romão}

é professor do Departamento de Antropologia, Política e Filosofia da FCL-Araraquara/Unesp, e pesquisador do Cebrap.

\section{Referências Bibliográficas}

AVRITZER, L. 1996. A moralidade da democracia: ensaios em teoria habermasiana e teoria democrática. São Paulo/Belo Horizonte: Perspectiva; Ed. da UFMG. . 2002a. Democracy and the public space in Latin America. Princeton/ Oxford: Princeton University Press. 2002b. "O orçamento participativo: as experiências de Porto Alegre e Belo Horizonte”. In: DAGNINO, E. (org.). Sociedade civil e espaços públicos no Brasil. São Paulo: Paz e Terra.

2003. "O orçamento participativo e a teoria democrática: um balanço crítico”. In: AVRITZER, L.; NAVARRO, Z. (orgs.). A inovação democrática no Brasil: o orçamento participativo. São Paulo: Cortez. 2005. "Modelos de deliberação democrática: uma análise do orçamento participativo no Brasil”. In: SANTOS, B. (org.). Democratizar a democracia: os caminhos da democracia participativa. Rio de Janeiro: Civilização Brasileira. 2009. Participatory institutions in democratic Brazil. Baltimore: Johns Hopkins University Press. 
; WAMPLER, B. 2004. "Públicos participativos: sociedade civil e novas instituições no Brasil democrático”. In: COELHO, V. S.; NOBRE, M. (orgs.). Participação e deliberação: teoria democrática e experiências institucionais no Brasil contemporâneo. São Paulo: Editora 34.

BAIERLE, S. 1992. Um novo princípio ético-político: prática social e sujeitos nos movimentos populares urbanos em Porto Alegre nos anos 80. Dissertação de mestrado. Campinas: IFCH-Unicamp. 2002. “OP ao termidor?”. In: VERLE, J.; BRUNET, L. (orgs.). Construindo um mundo novo: avaliação da experiência do Orçamento Participativo em Porto Alegre - Brasil. Porto Alegre: Guayí.

COELHO, V. S. 2007. "A democratização dos conselhos de saúde: o paradoxo de atrair não aliados”. Novos Estudos, n. 78, pp. 77-92. .; FAVARETO, A. 2007. "Dilemas da participação e desenvolvimento territorial”. In: DAGNINO, E.; TATAGIBA, L. (orgs.). Democracia, sociedade civil e participação. Chapecó: Argos.

CARVALHO, M. C.; FELGUEIRAS, D. 2000. Orçamento participativo no ABC - Mauá, Ribeirão Pires e Santo André. São Paulo: Instituto Pólis.

CASTEllo, G.; GURZA LAVALLE, A.; HOUTZAGER, P. 2009.

"Organizações civis e representação política em instituições participativas no Brasil”. In: CORNWALL, A.; COELHO, V. S. (orgs.). Novos espaços democráticos: perspectivas internacionais. São Paulo: Singular/Esfera Pública.

CORNWALL, A. 2009. "A democratização da administração dos serviços de saúde: o caso do Cabo de Santo Agostinho, Brasil”. In: CORNWALL, A.; COELHO, V. S. (orgs.). Novos espaços democráticos: perspectivas internacionais. São Paulo: Singular; Esfera Pública.

DIAS, J. M. 2006. O orçamento participativo na cidade de São Paulo: confrontos e enfrentamentos no circuito do poder. Dissertação de mestrado. São Paulo: PUC-SP.

DIAS, M. R. 2002. Sob o signo da vontade popular: o Orçamento Participativo e o dilema da Câmara Municipal de Porto Alegre. Belo Horizonte, Rio de Janeiro: Ed. da UFMG/Iuperj.

FEDOZZI, L. 2001. Orçamento Participativo: reflexões sobre a experiência de Porto Alegre. Porto Alegre/Rio de Janeiro: Tomo Editorial/UFRJ IPPUR.

FELTRAN, G. 2006. "Deslocamentos - trajetórias individuais, relações entre sociedade civil e Estado no Brasil”. In: DAGNINO, E.; OLVERA, A.; PANFICHI, A. (orgs.). A disputa pela construção democrática na América Latina. São Paulo/Campinas: Paz e Terra/Ed. da Unicamp.

FILOMENA, C. 2006. O agonismo nas relações sociais do partido, dos espaços públicos da sociedade civil e do sistema administrativo estatal: a experiência 
da Administração Popular em Porto Alegre. Dissertação de mestrado, Porto Alegre, PUC-RS.

GOLDMAN, M. 2006. Como funciona a democracia: uma teoria etnográfica da política. Rio de Janeiro: 7 Letras.

GURZA LAVALLE, A. 2003. "Sem pena nem glória: o debate sobre a sociedade civil nos anos 1990". Novos Estudos, n. 66, pp. 91-109. ; HOUTZAGER, P.; ACHARYA, A. 2004. "Lugares e atores da democracia: arranjos institucionais participativos e sociedade civil em São Paulo”. In: COELHO, V. S.; NOBRE, M. (orgs.). Participação e deliberação: teoria democrática e experiências institucionais no Brasil contemporâneo. São Paulo: Editora 34.

HOUTZAGER, P.; GURZA LAVALLE, A.; ACHARYA, A. 2004. "Atores da sociedade civil e atores políticos: participação nas novas políticas democráticas em São Paulo”. In: AVRITZER, L. (org.). A participação em São Paulo. São Paulo: Ed. da Unesp.

MAIA, R. 2010. "O papel democrático da sociedade civil em questão". Lua Nova, n. 81, pp. 147-174.

MARQUETTI, A.; CAMPOS, G.; PIRES, R. 2008. Democracia participativa e redistribuição: análise de experiências de orçamento participativo. São Paulo: Xamã.

NEVES, A. 2008. Cultura política e democracia participativa: um estudo sobre o orçamento participativo. Rio de Janeiro: Gramma/Faperj.

NYLEN, W. R. 2002. "Testing the empowerment thesis: the participatory budget in Belo Horizonte \& Betim, Brazil”. Comparative Politics, n. 34, pp. 127-145.

OTTMANN, G. 2006. "Cidadania mediada: processos de democratização da política municipal no Brasil”. Novos Estudos, n. 74, pp. 155-175.

PANEBIANCO, A. 2005. Modelos de partido: organização e poder nos partidos políticos. São Paulo: Martins Fontes.

PEREIRA, E. 2007. O OP (Orçamento Participativo) como processo de educação política: um estudo da histórica experiência de Várzea Paulista-SP. Tese de doutorado. Campinas: IFCH-Unicamp.

PONTUAL, P. 2000. O processo educativo no Orçamento Participativo: aprendizados dos atores da sociedade civil e do Estado. Tese de doutorado. São Paulo: PUC-SP.

RICCI, R. 2004. "Associativismo paulistano e cultura ambivalente”. In: AVRITZER, L. (org.). A participação em São Paulo. São Paulo: Ed. da Unesp. RIZEK, C. 2007. "São Paulo: orçamento e participação". In: OLIVEIRA, F.; RIZEK, C. (orgs.). A era da indeterminação. São Paulo: Boitempo.

RODGERS, D. 2009. "Subvertendo os espaços participativos? Políticas locais e orçamento participativo na Buenos Aires pós-crise”. In: 
CORNWALL, A.; COELHO, V. S. (orgs.). Novos espaços democráticos: perspectivas internacionais. São Paulo: Singular/ Esfera Pública. ROMÃO, W. M. 2010a. Nas franjas da sociedade política: estudo sobre o orçamento participativo. Tese de doutorado. São Paulo: FFLCH-USP. ROMÃO, W. M. 2010b. "Entre a sociedade civil e a sociedade política: Participatory institutions in democratic Brazil”. Novos Estudos, n. 87, pp. 199-206.

SANCHEZ, F. 2002. Orçamento participativo: teoria e prática. São Paulo: Cortez. SILVA, M. 2003. Belo Horizonte e o orçamento participativo: harmonia e crise entre os diversos atores envolvidos no processo de decisão orçamentária. Dissertação de mestrado. São Paulo: FFLCH-USP.

SILVA, T. 2003. "Da participação que temos à que queremos: o processo do Orçamento Participativo na cidade do Recife". In: AVRITZER, L.; NAVARRO, Z. (orgs.). A inovação democrática no Brasil: o orçamento participativo. São Paulo: Cortez.

TEIXEIRA, A. C. 2003. "O OP em pequenos municípios rurais: contextos, condições de implementação e formatos de experiência”. In:

AVRITZER, L.; NAVARRO, Z. (orgs.). A inovação democrática no Brasil: o orçamento participativo. São Paulo: Cortez.

; TATAGIBA, L. 2005. Movimentos sociais e sistema político: os desafios da participação. São Paulo: Instituto Pólis/ PUC-SP.

WAMPLER, B. 2004. "Instituições, associações e interesses no orçamento participativo de São Paulo”. In: AVRITZER, L. (org.). A participação em São Paulo. São Paulo: Ed. da Unesp.

2007. Participatory budgeting in Brazil: contestation, cooperation, and accountability. University Park: The Pennsylvania State University Press. 